Check for updates

Cite this: RSC Adv., 2018, 8, 14138

Received 9th February 2018

Accepted 10th April 2018

DOI: $10.1039 / c 8 r a 01261 j$

rsc.li/rsc-advances

\section{Facile synthesis of urchin-like RuCu and hollow RuCuMo nanoparticles and preliminary insight to their formation process by cyclic voltammetry $\dagger$}

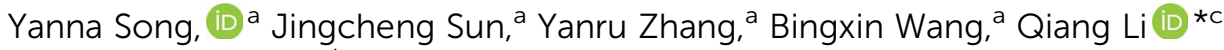 \\ and Yongming Fan ${ }^{\star a b}$
}

Urchin-like RuCu nanoparticles and hollow RuCuMo nanoparticles were prepared by a one-pot chemical reduction method. The nanoparticles were characterized by EDX, HRTEM, XPS and ICP-AES. By combining cyclic voltammetry and TEM, the formation process of nanoparticles was obtained. The urchin-like RuCu nanoparticles are proved to be formed via underpotential deposition mechanism and the formation of ternary nanoparticles RuCuMo was due to the replacement of $\mathrm{Cu}$ with $\mathrm{Ru}$ and the interception of Mo gradually. It was found that the formation of different morphology is depended on the precursors in the reaction system and their reduction sequences. Compared to previously reported multi-step synthetic routes, the developed method here is much simpler.

\section{Introduction}

The synthesis of multi-component metallic nanoparticles (NPs) has been a hot topic in the past decades because of their various important applications, such as optics, bioanalysis and catalysis. $^{1-5}$ Due to electronic and synergistic effects, multicomponent metallic NPs often show unique catalytic activities and superior selectivity and stability to monometallic counterparts. It has been reported to result from the introduction of transition metals (i.e., $\mathrm{Cu}, \mathrm{Co}, \mathrm{Ni}$, etc.) into noble-metal NPs, which enhances the catalytic activity and decreases the consumption of noble metals. Shevchenko et al. ${ }^{6}$ firstly reported the colloidal synthesis of monodisperse $\mathrm{CoPt}_{3}$ NPs with different sizes and high stability. Many efforts have been made therewith for the synthesis of NPs by solution reduction, ${ }^{7-9}$ electrochemical synthesis, ${ }^{10}$ and hydrothermal synthesis. ${ }^{11}$ However, the Ru-based NPs has been rarely reported. As an important platinum-group metal, $\mathrm{Ru}$ is comparatively cheaper and has been widely used in many important reactions such as CO oxidation, ${ }^{12}$ selective hydrogenation, ${ }^{13}$ and dehydrogenation of ammonia borane. ${ }^{14}$ Despite successful synthesis of Ru NPs with well-defined size and morphology ${ }^{15-21}$ the synthesis of Rubased NPs received limited success. ${ }^{22,23}$ A possible reason for

\footnotetext{
${ }^{a} \mathrm{MOE}$ Engineering Research Center of Forestry Biomass Materials and Bioenergy, Beijing Forestry University, Beijing, 100083, China

${ }^{b}$ Key Laboratory of Lignocellulosic Chemistry, Beijing Forestry University, Beijing 100083, China. E-mail: fanym@bjfu.edu.cn; Tel: +86-185-15301003

${ }^{c}$ College of Science, Beijing Forestry University, Beijing 100083, China. E-mail: liqiang@bjfu.edu.cn; Tel: +86-137-18679671

$\dagger$ Electronic supplementary information (ESI) available: Size distribution, EDX, CV curves. See DOI: 10.1039/c8ra01261j
}

this is that $\mathrm{Ru}$ is too active to be stable in oxidative environment. The introduction of a second or third party onto Ru could be a solution for this challenging problem. However, the synthesis of ternary Ru-based NPs has not been reported so far.

Understanding of the formation process of NPs is necessary for the design of catalyst with targeted properties. ${ }^{22}$ Zhu et al. have reported the synthesis of PtNi nanocrystals by tracing the $\mathrm{Ni}$ contents in particles with TEM and EDX at different reaction stages. ${ }^{24}$ Polte and his co-workers have presented the formation mechanism of gold NPs with the help of in situ small-angle X-ray scattering and $\mathrm{X}$-ray absorption near-edge spectroscopy. ${ }^{25}$ However, it still remains challenging to figure out the timedependent characterization of the formation process of those NPs.

Herein, a facile and effective approach was introduced to synthesize urchin-like RuCu NPs and hollow RuCuMo NPs. The products were characterized by TEM, HRTEM, XPS and ICP-AES and the formation process was monitored by measuring the cyclic voltammetric behaviors.

\section{Materials and methods}

\subsection{Materials}

Ruthenium(III) acetylacetonate $\left(\mathrm{Ru}(\mathrm{acac})_{3}, 99 \%\right)$ were purchased from Beijing HWRK Chem Co., LTD. Copper(II) acetylacetonate $\left(\mathrm{Cu}(\mathrm{acac})_{2}, 95 \%\right)$ were purchased from J. K Scientific. Poly(vinyl pyrrolidone) (PVP, MW 22000) were purchased from Xilong chemical. Sodium molybdate $\left(\mathrm{Na}_{2} \mathrm{MoO}_{4}, 95 \%\right)$, and benzyl alcohol $\left(\mathrm{C}_{6} \mathrm{H}_{5} \mathrm{CH}_{2} \mathrm{OH}, \geq 99.9 \%\right)$ were all purchased from SigmaAldrich. These chemicals were pure without further processing. 


\subsection{Synthesis of urchin-like RuCu NPs}

A series of control experiments under different reaction conditions were conducted. And the optimum conditions are as follows: $\mathrm{Ru}(\text { acac })_{3}(0.04 \mathrm{mmol}), \mathrm{Cu}(\text { acac })_{2}(0.04 \mathrm{mmol})$ and PVP (71 mg) dispersed in $\mathrm{C}_{6} \mathrm{H}_{5} \mathrm{CH}_{2} \mathrm{OH}(7.50 \mathrm{~mL})$ were added into a vial (volume: $30 \mathrm{~mL}$ ). After the vial had been capped, the mixture was sonicated for about 5 minutes. The resulting homogeneous mixture was then heated at $160{ }^{\circ} \mathrm{C}$ for $8 \mathrm{~h}$ in an oil bath and then cooled down to room temperature after reaction. The resulting colloidal products were collected and washed five times with acetone by centrifugation.

\subsection{Synthesis of hollow RuCuMo NPs}

A series of control experiments under different reaction conditions were conducted. And the optimum conditions are as follows: $\mathrm{Ru}(\mathrm{acac})_{3} \quad(0.04 \mathrm{mmol}), \mathrm{Cu}(\mathrm{acac})_{2} \quad(0.04 \mathrm{mmol})$, $\mathrm{Na}_{2} \mathrm{MoO}_{4}(0.04 \mathrm{mmol})$ and PVP (71 $\left.\mathrm{mg}\right)$ dispersed in $\mathrm{C}_{6} \mathrm{H}_{5} \mathrm{CH}_{2} \mathrm{OH}(7.50 \mathrm{~mL})$ were added into a vial (volume: $30 \mathrm{~mL}$ ). After the vial had been capped, the mixture was sonicated for about 5 minutes. The resulting homogeneous mixture was then heated at $160{ }^{\circ} \mathrm{C}$ for $8 \mathrm{~h}$ in an oil bath and then cooled down to room temperature after reaction. The resulting colloidal products were collected and washed five times with ethanol by centrifugation.

\subsection{Characterizations}

The transmission electron microscope (TEM) images were taken using a Hitachi-7700 microscope operated at $100 \mathrm{kV}$. The energy dispersive X-ray (EDX) analysis and high-angle annular dark-field scanning TEM (HAADF-STEM) analysis were performed using high resolution transmission electron microscopy (HRTEM, JEM 2100F) at $200 \mathrm{kV}$. The samples for TEM observation were prepared by dispersing the metal nanoparticles in ethanol at room temperature and then transferred on a carboncoated nickel grid. The size distribution of 150 NPs was measured with Nano Measurer software. X-ray photoelectron spectroscopy (XPS) experiments were performed on PHI-5300 Quantera microprobe. The element composition of NPs was determined by the inductively coupled plasma atomic emission spectroscopy (ICP-AES, IRIS Intrepid II).

\subsection{Cyclic voltammetry analysis}

The cyclic voltammetry analysis were performed using a $\mathrm{CHI}$ 660E electrochemical analyzer (CH Instrument, Chenhua Co., Shanghai, China) in a conventional three-electrode system including an $\mathrm{Ag} / \mathrm{AgCl}$ (saturation $\mathrm{KCl}$ ) reference electrode, a glassy carbon working electrode, and a platinum wire counter electrode. The glassy carbon electrode was polished with slurry of $0.5 \mu \mathrm{m}$ and $0.05 \mu \mathrm{m}$ alumina to mirror, ultrasonically washed in ethanol and deionized water for $20 \mathrm{~min}$ and dried at room temperature. The catalyst nano powder was suspended in $1 \mathrm{~mL}$ ethanol and $50 \mu \mathrm{L}$ Nafion solution (5\%) in ultrasonic for $20 \mathrm{~min}$ to make the homogeneous catalyst ink. The $10 \mu \mathrm{L}$ catalyst ink was dropped onto the clean surface of the glassy carbon electrode. It is dried at room temperature to form a working electrode. The CV measurements are performed in $\mathrm{N}_{2}$-saturated $0.5 \mathrm{M} \mathrm{H}_{2} \mathrm{SO}_{4}$ solution at a scanning rate of $10 \mathrm{mV} \mathrm{s}^{-1}$. The $\mathrm{CV}$ curves were measured by running 500 times to ensure reproducibility.

\section{Results and discussion}

TEM and HAADF-STEM images were taken to probe the morphology of the as-synthesized RuCu sample. As shown in Fig. 1, the most of the particles are in urchin-like shape. The diameter of the particles ranges from $21 \mathrm{~nm}$ to $33 \mathrm{~nm}$ (Fig. 1a and S1, ESI $\dagger$ ). The EDX elemental mapping (Fig. 1c) and linescanning images (Fig. S2a, ESI $\dagger$ ) showed the structure of $\mathrm{RuCu}$ NPs. It was revealed that $\mathrm{Ru}$ and $\mathrm{Cu}$ element are uniformly distributed on the entire NPs, implying the formation of RuCu alloy. Both the EDX (Fig. S2b, ESI $\dagger$ ) and ICP-AES analysis displayed the similar $\mathrm{Ru}: \mathrm{Cu}$ atomic ratio of about $0.69: 0.31$. This atomic ratio was higher than the $\mathrm{Ru} / \mathrm{Cu}$ stoichiometric ratio in the reaction system $\left(\mathrm{Ru}(\mathrm{acac})_{3} / \mathrm{Cu}(\mathrm{acac})_{2}\right.$ $(1: 1)$ ), which could be caused by the dissolution of un-alloyed $\mathrm{Cu}$ during washing step. The signal of $\mathrm{Ni}$ in Fig. S2b (ESI $\dagger$ ) was originated from the nickel grid used in the measurement. The HRTEM images of RuCu NPs shows some similar urchin-like picture. The SAED image shows well crystallinity and the polycrystal structure (Fig. S3, ESI $\dagger$ ).

The XRD pattern of the RuCu NPs was shown in Fig. S4 (ESI $\dagger$ ). By comparing the XRD pattern of pure Ru standard card (JCPDS card no 06-0663), we found that the diffraction peaks of the prepared nanoparticles were all right-shifted, which were supposed to be caused by the addition of $\mathrm{Cu}$ in $\mathrm{Ru}$ crystal lattice, which changed the inter-planar spacing. The characteristic peaks of RuCu were between the two single metal peaks, indicating that the obtained material was $\mathrm{RuCu}$ alloy. The diffraction peaks of $\mathrm{RuO}_{2}(110)\left(2 \theta=28.0^{\circ}\right)$ (JCPDS card no 43-1027) appeared in Fig. S4 (ESI $\dagger$ ) suggest the presence of Ru oxidation state $\left(\mathrm{RuO}_{2}\right)$.
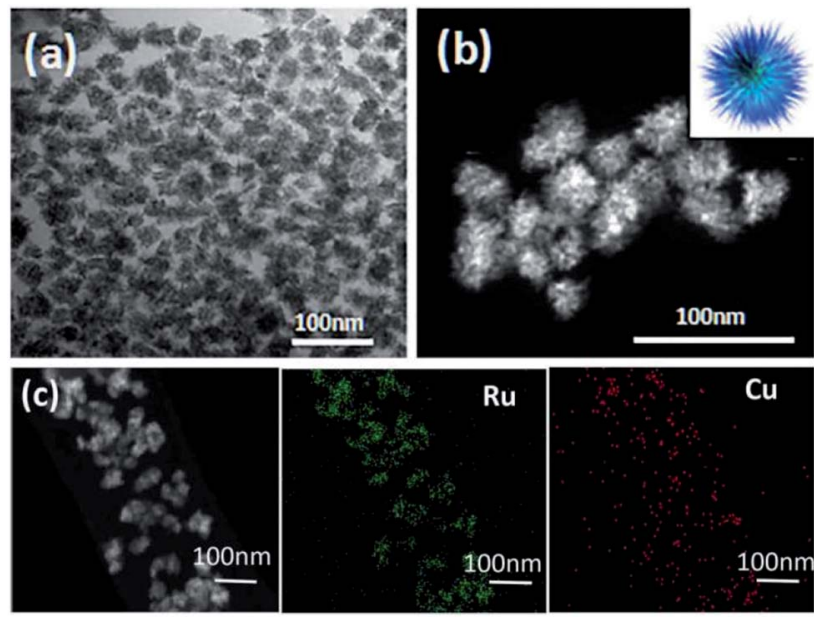

Ru

$\mathrm{Cu}$

Fig. 1 (a) TEM and (b) HAADF-STEM images of urchin-like RuCu (the inset in (b) is a schematic illustration of urchin-like RuCu); (c) EDX elemental mapping images. 

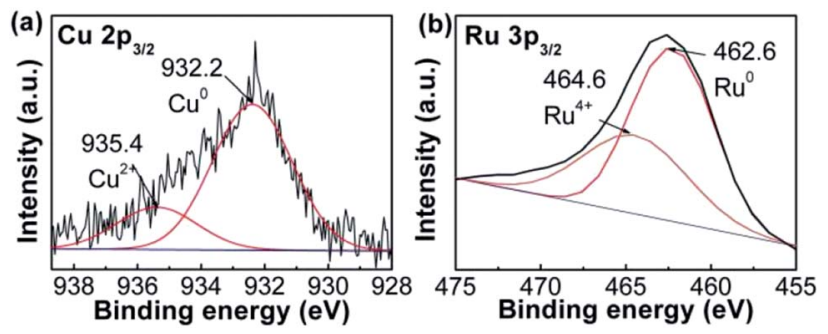

Fig. 2 (a) $C u 2 p_{3 / 2}$ and (b) Ru 3p $p_{3 / 2}$ XPS spectra of RuCu nanoparticles.

The compositions of RuCu sample were studied using XPS. The spectrum was separated into two peaks (Fig. 2a). The peak at $\sim 932.2 \mathrm{eV}$ is attributed to $\mathrm{Cu}^{0}$, while that at $\sim 935.4 \mathrm{eV}$ corresponds to $\mathrm{Cu}^{2+}$ in RuCu NPs. The content of $21.7 \% \mathrm{Cu}^{2+}$ in RuCu NPs was based on the peak area. The same protocol was applied to $\mathrm{Ru} 3 \mathrm{p}_{3 / 2}$ spectrum (Fig. $2 \mathrm{~b}$ ). The peak at $\sim 462.6 \mathrm{eV}$ was attributed to $\mathrm{Ru}^{0}$ and that at $\sim 464.6 \mathrm{eV}$ was assigned to $\mathrm{Ru}^{4+}$ $\left(\mathrm{RuO}_{2}\right),{ }^{26}$ which is assistent with XRD result. $26.9 \%$ of $\mathrm{Ru}^{4+}$ remained in the RuCu NPs.

In the control experiment using only Ru precursor in the synthesis, $7 \mathrm{~nm}$ Ru particles with uncontrollable shape are obtained (Fig. S5, ESI $\dagger$ ), while using only $\mathrm{Cu}$ precursor, even no particles were found. However, in the case of coexisted precursors of $\mathrm{Ru}$ and $\mathrm{Cu}$ in the synthesis, the urchin-like $\mathrm{RuCu}$ NPs were achieved. This suggested that coexistence of $\mathrm{Ru}$ and $\mathrm{Cu}$ was essential for the synthesis of urchin-like particle.

To study the formation process of NPs, cyclic voltammetry (CV) measurement was employed. CV curves corresponding to $50 \mathrm{~min}, 1 \mathrm{~h}, 1.5 \mathrm{~h}$, and $2 \mathrm{~h}$ respectively were showed in Fig. 3. The typical CV curves of ruthenium, copper, molybdenum NPs, $\mathrm{RuCu}$ and CuMo bimetallic NPs were obtained and displayed in Fig. S6 (ESI $\dagger$ ). The CV curve at $50 \mathrm{~min}$ is consistent with that of $\mathrm{Ru}$ NPs (Fig. S6b, ESI $\dagger$ ) and the CV curve at $2 \mathrm{~h}$ is agreement with that of RuCu NPs (Fig. S6d, ESI $\dagger$ ), suggesting that $\mathrm{Ru}^{3+}$ is reduced prior to $\mathrm{Cu}^{2+}$ during the reaction. Theoretically, the standard redox potential of $\mathrm{Ru}^{3+} / \mathrm{Ru}^{0}$ and $\mathrm{Cu}^{2+} / \mathrm{Cu}^{0}$ is $0.68 \mathrm{~V}$ and

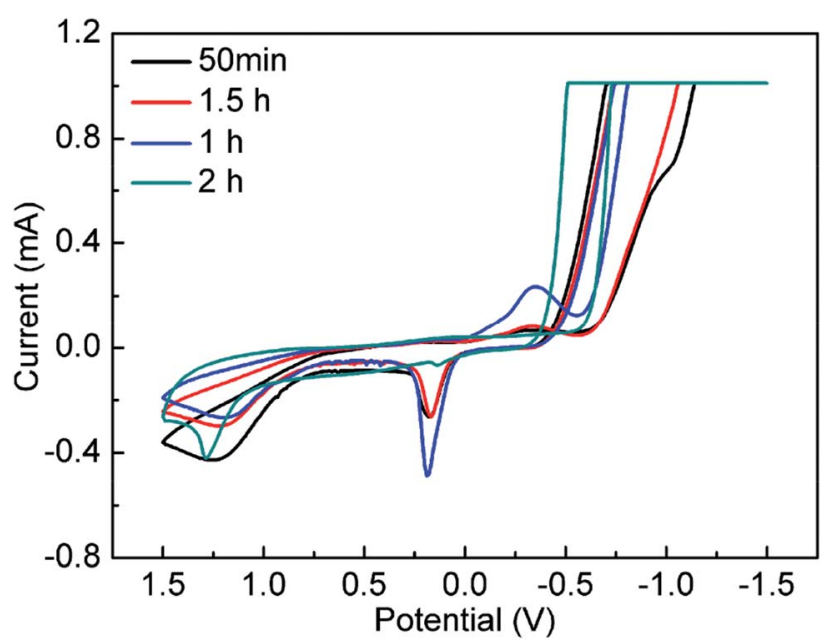

Fig. 3 The CV curves at different RuCu nanoparticles sampling time.

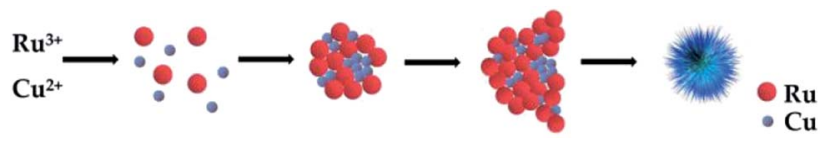

Fig. 4 Schematic illustration of the formation process of $\mathrm{RuCu}$ bimetallic nanoparticles.

$0.34 \mathrm{~V}$ respectively, so the reduction of $\mathrm{Ru}$ species should be easier than $\mathrm{Cu}$ species. ${ }^{27}$

Based on the results above, we postulated the formation process of RuCu NPs (Fig. 4). At the initial stage, $\mathrm{Ru}^{3+}$ and $\mathrm{Cu}^{2+}$ are reduced by benzyl alcohol but $\mathrm{Ru}$ atoms tend to be reduced in a faster rate than $\mathrm{Cu}$ and nucleate, grow first. At the second stage, by way of underpotential deposition effect, ${ }^{28}$ the produced $\mathrm{Cu}$ atoms are deposit on the formed $\mathrm{Ru}$ particles and form $\mathrm{RuCu}$ nuclei. At the third stage, $\mathrm{Ru}$ atoms grow in one direction on $\mathrm{RuCu}$ nuclei, which follows the process reported by Yoon etc. that $\mathrm{Ru}$ atoms tend to form hexagonal close-packed (hcp) structure ${ }^{29}$ and facilitate the orientation growth. Therefore, with the formation of $\mathrm{Ru}^{0}$ and deposition of $\mathrm{Cu}^{0}$, the urchin-like RuCu NPs are formed.

The inexpensive Mo has been reported as co-catalyst to increase NPs' activity. ${ }^{30}$ In order to form a NPs with the tertiary members, $\mathrm{Na}_{2} \mathrm{MoO}_{4}$ was added in the substrate. In the synthesis, we surprisingly found the formation of RuCuMo NPs (Fig. 5). In general, the hollow structure is formed by multiple steps, involving the construction of nanoparticle template, element growing on the surface of the template and the removing of the template. But the complexity and difficulty in the synthesis of this interesting material limited their utility in the practical application. ${ }^{31,32}$ In this work, the hollow nanostructure was obtained by just one-step reduction process and
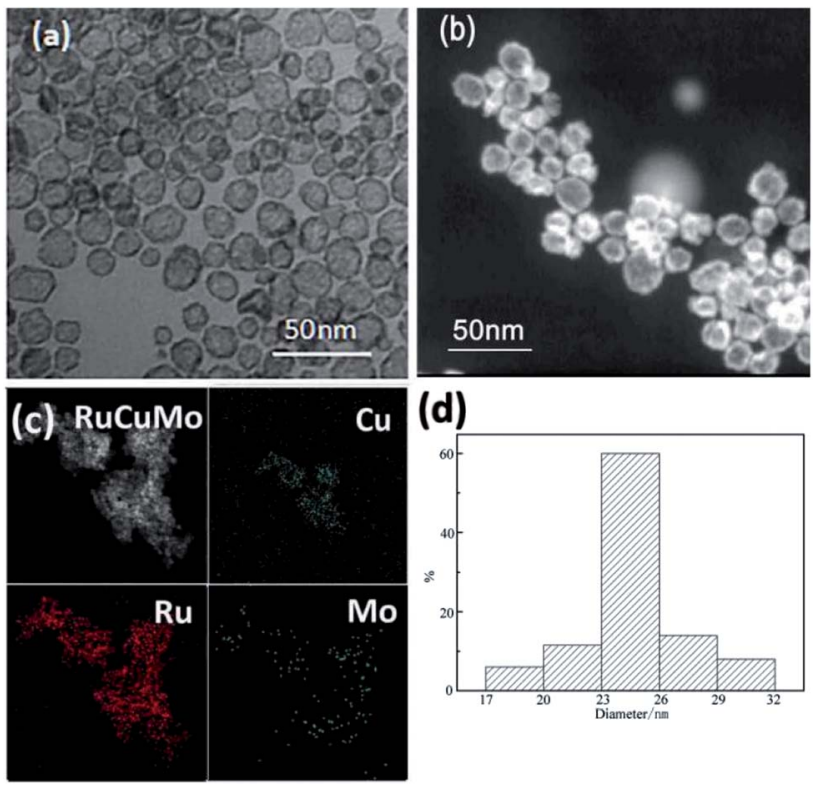

(d)

Fig. 5 (a) TEM and (b) HAADF-STEM images of hollow RuCuMo nanoparticles; (c) EDX elemental mapping images; (d) size distribution of hollow RuCuMo nanoparticles in (a). 
the results were displayed in Fig. 5. Fig. 5c shows the distribution of $\mathrm{Ru}, \mathrm{Cu}$ and Mo atoms, which confirms the formation of alloyed RuCuMo structure. The HRTEM images of RuCuMo NPs (Fig. S7a, ESI $\dagger$ ) displayed the hollow structure and the SAED image also showed the polycrystal structure (Fig. S7b, ESI $\dagger$ ). The diameter of the particles can be found in Fig. 5 a to be ranged from $17 \mathrm{~nm}$ to $32 \mathrm{~nm}$ (Fig. 5d). The EDX line scanning analysis of a single particle suggests that $\mathrm{Cu}$ and Mo species are mostly concentrated on the shell (Fig. S8, ESI $\dagger$ ). The signal difference between the edge and center gives another convincing evidence of the structure with hollow interior. ${ }^{334}$ ICP-AES analysis showed that the atomic ratio of $\mathrm{Ru}: \mathrm{Cu}: \mathrm{Mo}$ is $0.75: 0.20: 0.05$. It can be found that Mo made up a very small proportion in the produced nano particles. This should be caused by the slow reduction rate of Mo species due to the relatively low redox potential of $\mathrm{MoO}_{4}{ }^{2-} / \mathrm{Mo}(-1.05 \mathrm{~V} v s$. SHE $)$, which result in a low content of Mo in the final product.

For the XRD pattern of RuCuMo NPs in Fig. S9 (ESI $\dagger$ ), the three peaks were identified as the RuCuMo alloy, but shifted slightly to higher angles compared with the Ru metal standard (JCPDS no 06-0663). This peak shift is possibly resulted from the change in lattice parameters. Replacing the $\mathrm{Ru}$ position with $\mathrm{Cu}$ and Mo atoms will reduce the unit cell volume, ${ }^{35,36}$ resulting in a lattice parameters reduction. There was no standard JCPDS file can be referred to for the RuCuMo alloy. However, based on the XRD pattern obtained, we believe that the of RuCuMo alloy was formed due to the three characteristic peaks of the synthesized product were all among the three single metal characteristic peaks. The diffraction peaks of $\mathrm{RuO}_{2}(110)$ ( $2 \theta=$ $28.0^{\circ}$ ) (JCPDS card no 43-1027) appeared once again, suggesting the presence of $\mathrm{Ru}$ oxidation state $\left(\mathrm{RuO}_{2}\right)$.

The NPs can be achieved in $10 \mathrm{~min}$ in ternary system, however, it takes $50 \mathrm{~min}$ to form NPs in binary system. It suggests that the reduction of the metal precursors can be promoted by the addition of $\mathrm{Na}_{2} \mathrm{MoO}_{4}$. PVP has been reported to be used as the capping agent and weaker reducer in the published works, we found in this work that the addition of PVP in the reaction system could prevent the formed particles from being aggregated (Fig. S10, ESI $\dagger$ ), which may be due to the capping and reducing activity as reported. ${ }^{37,38}$

The XPS analysis displayed the bonding state of the metal atoms in RuCuMo NPs. The peaks at $\sim 233.1 \mathrm{eV}$ and $\sim 236.2 \mathrm{eV}$ could be assigned to $\mathrm{Mo}^{6+}$ state (Fig. 6a), which suggests the oxidation effect (Mo to $\mathrm{MoO}_{3}$ ) on the surface. ${ }^{39}$ Such oxidation of nanosized metals is normal. ${ }^{40}$ Fig. 6b shows $36.1 \% \mathrm{Cu}^{2+}$ in RuCuMo NPs. The $\mathrm{Ru}^{4+}$ ratio of RuCuMo NPs was declined to $21.1 \%$ from $26.9 \%$ of RuCu NPs. It is indicated that, compared with binary RuCu NPs, ternary RuCuMo NPs is more stable. The result indicates the combination of $\mathrm{Ru}$ and the modified nonnoble transition metals improves the stability due to the electron interaction of the elements. ${ }^{41}$

To understand the formation process of the ternary RuCuMo NPs, CV analysis was performed, as well as the analysis of electrode potential of $\mathrm{Ru}^{3+} / \mathrm{Ru}, \mathrm{Cu}^{2+} / \mathrm{Cu}$ and $\mathrm{MoO}_{4}{ }^{2-} / \mathrm{Mo}$ (Fig. 6d and e). The standard redox potential of $\mathrm{Ru}^{3+} / \mathrm{Ru}^{0}, \mathrm{Cu}^{2+} /$ $\mathrm{Cu}^{0}$ and $\mathrm{MoO}_{4}{ }^{2-} / \mathrm{Mo}$ is $0.68 \mathrm{~V}, 0.34 \mathrm{~V}$ and $-1.05 \mathrm{~V}$, respectively, ${ }^{\mathbf{8}, 42}$ therefore, $\mathrm{Ru}$ ion is more easily reduced than the other two metal ions. However, according to Fig. $6 \mathrm{~d}$ and S6 (ESI $\dagger$ ), the $\mathrm{CV}$ curve at $10 \mathrm{~min}$ is consistent with that of $\mathrm{Cu}$ NPs, then the CV curve at the 20 min agrees with RuCu NPs, which suggests the $\mathrm{Cu}$ nuclei is obtained at the initial stage, and then $\mathrm{Ru}^{3+}$ is reduced. In addition, the analysis of the electrode potential $\left(E_{\theta}^{\prime}\right)$ (Fig. 6e) shows that $E_{\theta}^{\prime}$ of $\mathrm{Ru}^{3+} / \mathrm{Ru}^{0}$ don't be changed $\left(E^{\prime}{ }_{\theta}=0.68\right.$ V) and $E_{\theta}^{\prime}$ of $\mathrm{Cu}^{2+} / \mathrm{Cu}^{0}$ is increased to $0.59 \mathrm{~V}$ from original $0.34 \mathrm{~V}$, which also suggests that the reduction of $\mathrm{Cu}^{2+}$ in this system could be easier. The reduction of $\mathrm{MoO}_{4}{ }^{2-} / \mathrm{Mo}$ was not seen in the process (Fig. 6e and S11c, ESI $\dagger$ ), which suggests that it is difficult to get reduced in this system due to its redox
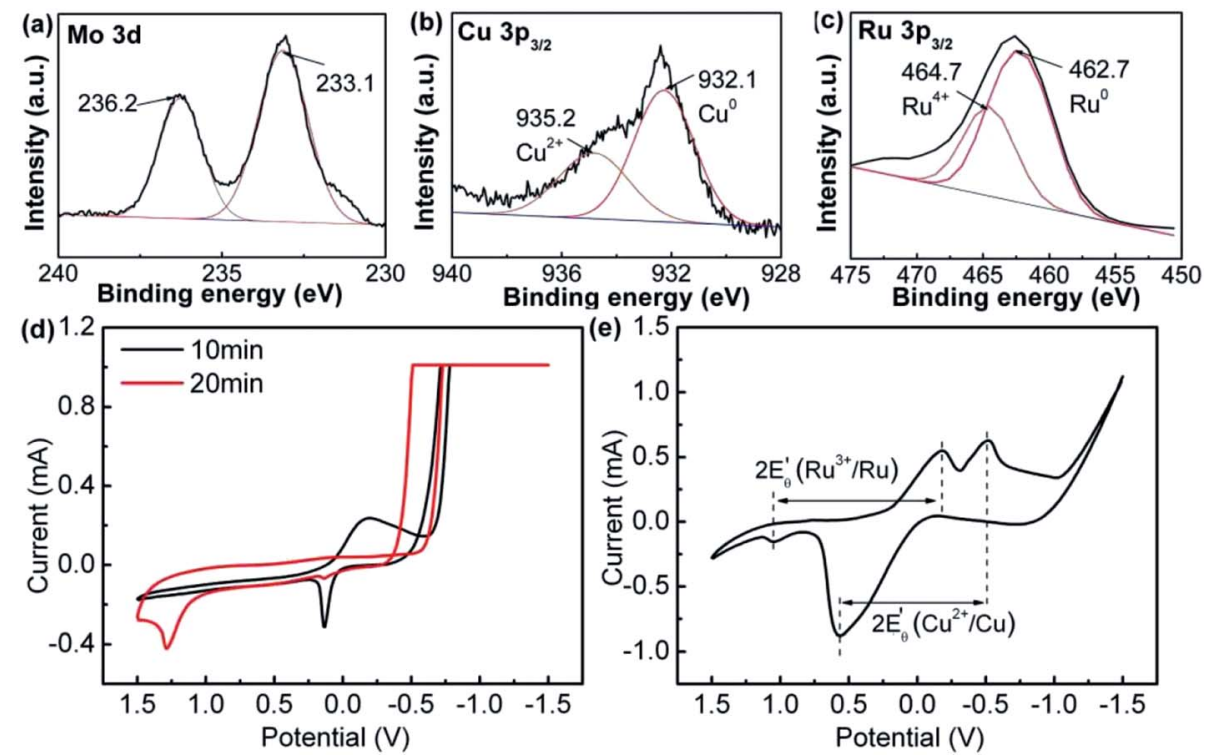

Fig. 6 (a) Mo 3d, (b) Cu 2p $p_{3 / 2}$ and (c) Ru 3p $p_{3 / 2}$ XPS spectra of RuCuMo nanoparticles; (d) the CV curves with different RuCuMo nanoparticles sampling time; (e) the electrode potential of $\mathrm{Ru}^{3+} / \mathrm{Ru} \mathrm{Cu}^{2+} / \mathrm{Cu}$ and $\mathrm{MoO}_{4}{ }^{2-} / \mathrm{Mo}$. 

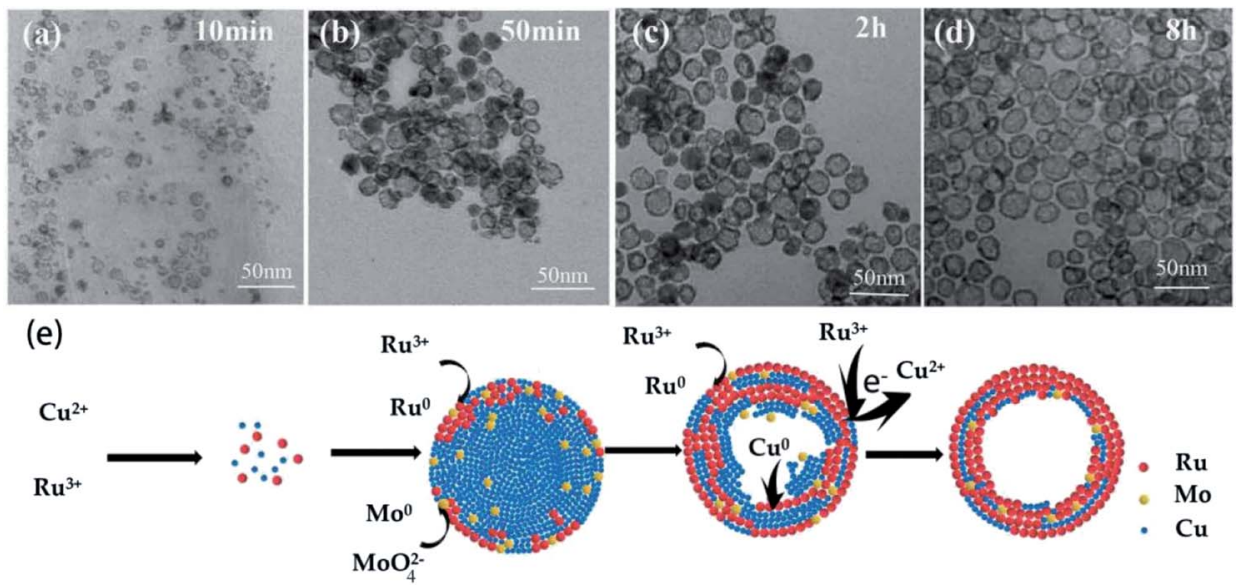

Fig. 7 Representative TEM images of the intermediates obtained at different reaction time during the synthesis of hollow RuCuMo nanoparticles: (a) $10 \mathrm{~min}$, (b) $50 \mathrm{~min}$, (c) $2 \mathrm{~h}$, and (d) 8 h, respectively. (e) Schematic illustration of the formation process of RuCuMo trimetallic nanoparticles.

potential. Therefore, the reduction of the ions is in the order of $\mathrm{Cu}^{2+}, \mathrm{Ru}^{3+}$ and then $\mathrm{MoO}_{4}{ }^{2-}$.

In order to further gain insight into the morphological evolution of RuCuMo NPs, typical TEM analysis of the samples at $10 \mathrm{~min}, 50 \mathrm{~min}, 2 \mathrm{~h}$ and $8 \mathrm{~h}$ respectively was performed (Fig. 7). At the initial stage, the NPs with the size of 3-10 nm are obtained at $10 \mathrm{~min}$ (Fig. 7a). The hollow particles were formed at 50 min (Fig. 7b) and the hollow structure with size of $\sim 23 \mathrm{~nm}$ were built at $8 \mathrm{~h}$ (Fig. $7 \mathrm{~d}$ ). Then the shape and size of the final products did not change with the reaction time.

Based on the discussion above, the formation mechanism of RuCuMo NPs is proposed in Fig. 7e. At the first stage, $\mathrm{Cu}$ and $\mathrm{Ru}$ precursors are reduced by $\mathrm{C}_{6} \mathrm{H}_{5} \mathrm{CH}_{2} \mathrm{OH}$. Due to the combination of $\mathrm{Ru}^{3+}$ and $\mathrm{MoO}_{4}{ }^{2-}$ at early stage, $\mathrm{Cu}^{2+}$ is reduced mainly in the initial phase. At the second stage, $\mathrm{Ru}$ atoms are preferentially positioned on the outer part of the formed $\mathrm{Cu} @ \mathrm{Ru}$ nano-nuclei because $\mathrm{Ru}$ atom is bigger in size than $\mathrm{Cu}$ atom. The reduction process is always accompanied with the diffusion process,$^{43}$ so the small proportion of Mo atoms are spread in the inner part of the hollow $\mathrm{Cu@Ru} \mathrm{particle} \mathrm{and} \mathrm{be} \mathrm{intercepted} \mathrm{among} \mathrm{Cu}$ and $\mathrm{Ru}$ atoms. At the third stage, $\mathrm{Cu}$ atoms are in situ oxidized by $\mathrm{Ru}^{3+}\left(\mathrm{Cu}(\mathrm{s})+2 \mathrm{Ru}^{3+} \rightarrow 3 \mathrm{Cu}^{2+}+\mathrm{Ru}(\mathrm{s})\right)$ due to the galvanic replacement reaction. ${ }^{44}$ Finally, the oxidized $\mathrm{Cu}$ atoms are removed from the solid NPs by dissolution into the solvent and the pits are filled with $\mathrm{Ru}$ atoms. The removal of $\mathrm{Cu}$ atoms makes the particle hollow inside.

\section{Conclusions}

In conclusion, we have successfully synthesized urchin-like $\mathrm{RuCu}$ and hollow RuCuMo NPs by one-pot reduction method. The morphology of the NPs is dependent upon the precursors in the reaction system and their reduction sequences. Compared to previously reported multi-step synthetic routes, the developed method here is much simpler. It is believed that cyclic voltammetry analysis can provide a profound information for synthesis of NPs.

\section{Conflicts of interest}

There are no conflicts to declare.

\section{Acknowledgements}

This work was supported by the National Natural Science Foundation of China (No. 21671021), the Fundamental Research Funds for the Central Universities (No. 2015ZCQ-LY03) and the Special Science and Technology Research Program of Beijing Forestry University (No. 2016KJ02).

\section{Notes and references}

1 A. R. Tao, S. S. Habas and P. D. Yang, Small, 2008, 3, 310-325. 2 Y. N. Xia, Y. J. Xiong, B. Lim and S. E. Skrabalak, Angew. Chem., Int. Ed., 2009, 48, 60-103.

3 B. Wiley, Y. G. Sun, B. Mayers and Y. N. Xia, Chem.-Eur. J., 2005, 11, 454-463.

4 X. Lai, C. Wang, Q. Jin, R. Yu and D. Wang, Sci. China Mater., 2015, 58, 192-197.

5 Q. Zhang, Z. Y. Hai, A. Q. Jian, H. Y. Xu, C. Y. Xue and S. B. Sang, Nanomaterials, 2016, 6, 138-149.

6 E. V. Shevchenko, D. V. Talapin, A. L. Rogach, A. Kornowski, M. Haase and H. Weller, J. Am. Chem. Soc., 2002, 124, 1148011485.

7 T. Xia, J. Liu, S. Wang, C. Wang, Y. Sun and R. Wang, Sci. China Mater., 2017, 60, 57-67.

8 B. Xia, H. Wu, X. Wang and X. Lou, J. Am. Chem. Soc., 2012, 134, 13934-13937.

9 C. Zhong, J. Liu, Z. Ni, Y. Deng, B. Chen and W. Hu, Sci. China Mater., 2014, 57, 13-25.

10 Y. H. Chang, C. Liu, S. Rouvimov, T. Luo and S. P. Feng, Chem. Commun., 2017, 53, 6752-6755.

11 W. F. Rao, Q. S. Zhu, Q. Ren, C. C. Wu and J. H. Miao, J. Electron. Mater., 2017, 46, 5303-5307.

12 F. Su, L. Lv, F. Lee, T. Liu, A. I. Cooper and X. Zhao, J. Am. Chem. Soc., 2007, 129, 14213-14223. 
13 C. Xiao, Z. Cai, T. Wang, Y. Kou and N. Yan, Angew. Chem., Int. Ed., 2008, 47, 746-749.

14 H. Ye, Q. Wang, M. Catalano, N. Lu, J. Vermeylen, M. J. Kim, Y. Liu, Y. Sun and X. Xia, Nano Lett., 2016, 16, 2812-2817.

15 M. Vanden Brink, M. A. Peck, K. L. More and J. D. Hoefelmeyer, J. Phys. Chem. C, 2008, 112, 12122-12126.

16 A. Ponrouch, S. B. Garbarino, S. P. Pronovost, P. Taberna, P. Simon and D. Guay, J. Electrochem. Soc., 2010, 157, K59K65.

17 M. Guo, G. Lan, J. Peng, M. Li, Q. Yang and C. Li, J. Mater. Chem. A, 2016, 4, 10956-10963.

18 P. Lignier, R. Bellabarba, R. P. Tooze, Z. Su, P. Landon, H. Ménard and W. Zhou, Cryst. Growth Des., 2012, 12, 939942.

19 J. H. Jang, J. Kim, Y. H. Lee, I. Y. Kim, M. H. Park, C. W. Yang, S. J. Hwang and Y. U. Kwon, Energy Environ. Sci., 2011, 4, 4947.

20 A. Yin, W. Liu, J. Ke, W. Zhu, J. Gu, Y. Zhang and C. Yan, J. Am. Chem. Soc., 2012, 134, 20479-20489.

21 J. Watt, C. L. Yu, S. L. Y. Chang, S. Cheong and R. D. Tilley, J. Am. Chem. Soc., 2013, 135, 606-609.

22 B. Lim, M. Jiang, T. Yu, P. H. C. Camargo and Y. Xia, Nano Res., 2010, 3, 69-80.

23 G. Chen, J. Zhang, A. Gupta, F. Rosei and D. Ma, New J. Chem., 2014, 38, 1827-1833.

24 E. Zhu, Y. Li, C. Chiu, X. Huang, M. Li, Z. Zhao, Y. Liu, X. Duan and Y. Huang, Nano Res., 2016, 9, 149-157.

25 J. Polte, T. T. Ahner, F. Delissen, S. Sokolov, F. Emmerling, A. F. Thünemann and R. Kraehnert, J. Am. Chem. Soc., 2010, 132, 1296-1301.

26 K. Qadir, S. H. Joo, B. S. Mun, D. R. Butcher, J. R. Renzas, F. Aksoy, Z. Liu, G. A. Somorjai and J. Y. Park, Nano Lett., 2012, 12, 5761-5768.

27 Y. Chen, Z. Yu, Z. Chen, R. Shen, Y. Wang, X. Cao, Q. Peng and Y. Li, Nano Res., 2016, 9, 2632-2640.
28 K. H. Choi, Y. J. Jang, D. Y. Chung, P. Seo, S. W. Jun, J. E. Lee, M. H. Oh, M. Shokouhimehr, N. Jung, S. J. Yoo and Y. E. Sung, Chem. Commun., 2016, 52, 597-600.

29 D. Yoon, S. Park, J. Park, J. Kim, H. Baik, H. Yang and K. Lee, Nanoscale, 2014, 6, 12402-12497.

30 N. Kakati, J. Maiti, S. H. Lee and Y. S. Yoon, Int. J. Hydrogen Energy, 2012, 37, 19055-19064.

31 Y. Hu, A. Zhu, Q. Zhang and Q. Liu, J. Power Sources, 2015, 299, 443-450.

32 G. Z. Chen, R. Rosei, F. Rosei and D. Ma, Chem. Commun., 2012, 48, 8009-8011.

33 T. Li, H. You, M. Xu, X. Song and J. Fang, ACS Appl. Mater. Interfaces, 2012, 4, 6942-6948.

34 X. Wang, J. Feng, Y. Bai, Q. Zhang and Y. Yin, Chem. Rev., 2016, 116, 10983-11060.

35 Y. J. Li, F. X. Quan, K. Chen, L. Chen and C. F. Chen, Catal. Today, 2016, 278, 247-254.

36 K. Z. Yang, L. Q. Zhou, X. Xiong, M. L. Ye, L. Li and Q. H. Xia, Microporous Mesoporous Mater., 2015, 225, 1-8.

37 M. V. Bandulasena, G. T. Vladisavljević, O. G. Odunmbaku and B. Benyahia, Chem. Eng. Sci., 2017, 171, 233-243.

38 Z. J. Pang, M. L. Zhang, L. Huang, R. C. Wen, J. T. Lu, Y. Zhao, A. X. Wei, L. L. Tao, D. X. Luo, J. Liu, Y. B. Yang, Y. Xiao and Z. M. Xiao, Mater. Lett., 2018, 210, 66-69.

39 Z. Song, T. Cai, Z. Chang, G. Liu, J. A. Rodriguez and J. Hrbek, J. Am. Chem. Soc., 2003, 125, 8059-8066.

40 R. Wang, L. Jiang, J. Feng, W. Liu, J. Yuan and A. Wang, Int. J. Hydrogen Energy, 2017, 42, 6695-6704.

41 H. Mao, T. Huang and A. Yu, J. Alloys Compd., 2016, 676, 390396.

42 D. Li, Electrochemical principle, Beihang University Press, China, 2008, p. 384.

43 D. Ma, X. Shi and A. Hu, Nanomaterials, 2016, 6, 218-227.

44 X. Huang, Y. Chen, C. Chiu, H. Zhang, Y. X. Xu, X. Duan and Y. Huang, Nanoscale, 2013, 5, 6284-6290. 